\title{
Impact of Raised Blood Glucose Level on In-Hospital Outcome of Thrombolysed Patients with Acute Myocardial Infarction
}

\author{
Musammat Sufia Akhter ${ }^{1}$, Md. Faruque ${ }^{2}$, Md. Toufiqur Rahman ${ }^{3}$, Mohammad Arifur Rahman ${ }^{4}$ \\ Mirza Abul Kalam Mohiuddin ${ }^{5}$ Sheikh Ziarat Islam 6
}

\begin{abstract}
:
Background: Diabetes mellitus (DM) is an established major cardiovascular risk factor associated with increased prevalence of coronary artery disease (CAD). Patients with diabetes often have numerous concomitant cardiac risk factors with a higher incidence of acute myocardial infarction (AMI) and congestive heart failure (CHF). Patients either with or without a prior history of DM may present with hyperglycemia during AMI. We analysed our population to determine whether admission hyperglycemia was a strong risk factor for in-hospital mortality and morbidity in patients with AMI and may be even stronger than a previous history of diabetes.In-hospital death risk of AMI patients without DM was about 2 to 4 times higher in patients with hyperglycemia than in those without hyperglycemia.

Methods:This Prospective observational study was carried out at the National Institute of Cardiovascular Diseases (NICVD), Dhaka. A total number of 200 STsegment elevation AMI patients were enrolled in this study as per inclusion and exclusion criteria. They were subdivided on the basis of admission blood glucose into two groups. Group-1A and 2A were 50 patients with blood glucose $<200 \mathrm{mg} / \mathrm{dl}(<11.1 \mathrm{mmol} / \mathrm{l})$ and Group-1B and 2B were 50 patients with blood glucose $\geq 200 \mathrm{mg} / \mathrm{dl}$ (11.1 $\geq \mathrm{mmol} / \mathrm{l})$. The numerical data obtained from the study were analyzed and significance of differences were estimated by using statistical methods. Computer based SPSS (Statistical Package for Social Science) were used.
\end{abstract}

Results:In the present study mean age of the male and female were $56.10 \pm 11.86$ and $57.83 \pm 13.74$ years, $p>0.05 \%$. There was no significant difference regarding risk factors and smoking was higher in both group. Regarding inhospital adverse outcome, death was significantly higher in hyperglycemic non diabetic group $(p<0.0001)$. It was two times $(56 \%)$ higher than diabetic hyperglycemic $(28 \%)$ group.Cardiogenic shock (66\%) and CHF (56\%) were also more common in hyperglycemic non diabetic group. Lowest patients $(8 \%)$ died of AMI without DM with random blood glucose $<11.1 \mathrm{mmol} / \mathrm{l}$ (controlled). On the other hand highest improvement was in the controlled group $(p<0.0001)$.Multivariate analysis showed Diabetic status with normal blood sugar was a predictor of adverse outcome; but patients with hyperglycemia and no history of diabetes had a worse outcome and were independently associated with significant risk of in-hospital mortality. Age group >65 years and Male sex were also associated with significant in-hospital mortality.

Conclusion: Independent of diabetic status, the occurrence of hyperglycemia during AMI is associated with a subpopulation of patients at particularly high risk for an adverse clinical outcome. Even with the highly efficacious treatment strategies currently available, persons presenting with AMI and hyperglycemia are at increased risk for cardiogenic shock and CHF or death in hospital.

Key Wards: Diabetes mellitus, In-hospital outcome, Acute myocardial infarction.

1. Assistant Professor, Department of Cardiology, National Institute of Cardiovascular Disease, Dhaka, Bangladesh.

2. Professor of Cardiology, Department of Cardiology (Ex.), National Institute of Cardiovascular Disease, Dhaka, Bangladesh.

3. Professor, Department of Cardiology, Colonel Malek Medical College, Majikganj.

4. Junior Consultant, Department of Cardiology, National Institute of Cardiovascular Disease, Dhaka, Bangladesh.

5. Senior Consultant, Department of Cardiac Surgery, United Hospital Ltd., Dhaka Bangladesh.

6. Associate Professor, Department of Cardiology, National Institute of Cardiovascular Disease, Dhaka, Bangladesh.

Address of Correspondence: Dr. Musammat Sufia Akhter, Assistant Professor, Department of Cardiology, National Institute of Cardiovascular Disease, Dhaka, Bangladesh. E-mail: drmusammatsufia@gmail.com, Mobile: 01552402498.

DOI: https://doi.org/10.3329/bhj.v35i1.49138

Copyright ( $\subseteq 2017$ Bangladesh Cardiac Society. Published by Bangladesh Cardiac Society. This is an Open Access articles published under the Creative Commons Attribution-NonCommercial 4.0 International License (CC BY-NC). This license permits use, distribution and reproduction in any medium, provided the original work is properly cited and is not used for commercial purposes. 


\section{Introduction}

Diabetes mellitus (DM) is an established major cardiovascular risk factor associated with increased prevalence of coronary artery disease (CAD). ${ }^{1}$ Patients with diabetes often have numerous concomitant cardiac risk factors with a higher incidence of acute myocardial infarction (AMI) and congestive heart failure (CHF). Patients either with or without a prior history of DM may present with hyperglycemia during AMI. Several studies have reported an association between elevated blood glucose upon admission and subsequent increased adverse events including $\mathrm{CHF}$, cardiogenic shock and death. ${ }^{2}$

In-hospital death risk of AMI patients without DM was about 2 to 4 times higher in patients with hyperglycemia than in those without hyperglycemia. ${ }^{3}$ Higher myocardial necrotic markers and lower left ventricular ejection fraction (LVEF) in patients of AMI without DM with hyperglycemia. ${ }^{4}$ Hyperglycemia itself is arrhythmogenic , due to prolongation of QT interval that may favour the occurrence of arrhythmias like ventricular tachycardia/ ventricular fibrillation, with potential fatal outcome more in patients of AMI without DM. ${ }^{4}$

Hyperglycemia activates thrombosis. Namely acute blood sugar level increase induces alteration in coagulation by shortening of fibrinogen half -life increases of pro-thrombin fragments and factor VII, together with enhanced platelet aggregation resulting in thromboembolic manifestation. ${ }^{5}$ An estimated 170 million people are affected by diabetes- the majority by type 2 diabetes. The top ten countries, in terms of absolute numbers of individuals with the condition, are India, China, United States, Indonesia, Japan, Russia, Brazil, Italy, and Bangladesh. ${ }^{6} \mathrm{~A}$ higher percentage of the hyperglycemic non-diabetic suffered cardiac arrest before admission compared with hyperglycemic DM (15\% and $2 \%$ respectively). ${ }^{7}$

The high prevalence of undiscovered abnormal glucose metabolism among patients with AMI, compatible with the pre-diabetic state as well as frank diabetes, may in part explain the association between admission glucose levels and mortality, especially in subjects who are not diagnosed as having diabetes at the time of the AMI. ${ }^{8}$ Another recent report showed that in patients without a history of DM, there was a linear relation between admission glucose and in hospital mortality. Impaired glucose tolerance and DM are common after an attack of AMI.These patients developed more adverse cardiovascular events like $\mathrm{CHF}$, angina as compared to patients with normal glucose tolerance. ${ }^{9}$
Diabetic women with coronary heart disease had more severe atherosclerotic lesion in comparison to diabetic men. CAD in diabetic women was also more diffuse than that of diabetic men. ${ }^{10}$ Another recent study showed that cardiogenic shock as well as death was significantly higher in patients with AMI with impaired fasting glucose (IFG). ${ }^{11}$ There was no such study carried out in our country to see the association between admission blood glucose level and the short term mortality risk in patients with STSegment elevation AMI who received thrombolytic, with the emphasis on whether the patients had a previous history of diabetes or not. So the proposed study might be quite justified and time worthy.

\section{Materials and methods}

This prospective observational study was conducted in National Institute of Cardiovascular Disease (NICVD), Dhaka. A total of 200 ST-segment elevation AMI patients with or without a history of DM admitted in coronary care unit (CCU) of NICVD who received thrombolytic were studied. Plasma Glucose was measured on admission. On the basis of history of DM, patients were divided into two groups one is (Group-1) where there were $100 \mathrm{AMI}$ patients without undiagnosed DM; another is (Group-2) where there were $100 \mathrm{AMI}$ patients with diagnosed DM.

The patients were again subdivided on the basis of admission blood glucose into two groups. Out of 100 patients in Group-1,subdivided into Group-1A: (50) were AMI without undiagnosed DM with admission blood glucose $<200 \mathrm{mg} / \mathrm{dl}(<11.1 \mathrm{mmol} / \mathrm{l})$ and other Group-1B: 50 were $\mathrm{AMI}$ without undiagnosed DM with admission blood glucose e"200mg/dl(11.1e"mmol/l). On the other hand, other 100 patients in Group-2,subdivided into Group-2A: (50) were AMI with diagnosed DM with admission blood glucose $<200 \mathrm{mg} / \mathrm{dl}(<11.1 \mathrm{mmol} / \mathrm{l})$ and other Group-2B: 50 were AMI with diagnosed DM with admission blood glucose e"200mg/dl(11.1 mmol/l).

The strength of association of glycemic status will be assessed by comparison of the two groups with a disordered blood glucose profile to the "normal"(control) Group-1 (A) patients not previously diagnosed with diabetes and with a random blood sugar $<200 \mathrm{mg} / \mathrm{dl}$ ( $<11.1 \mathrm{mmol} / \mathrm{l})$. All patients were followed up maximum up to 5 to 12 days after admission to see the In-hospital adverse outcome likely mortality \& morbidity (CHF, Cardiogenic shock/Hypotension, Arrhythmia, Thromboembolism and in-hospital stay.

The numerical data obtained from the study were analyzed and significance of differences were estimated by using statistical methods. Computer based SPSS 
(Statistical Package for Social Science, version 20) were used. Data were expressed in percentage, frequencies and means and standard deviation, as applicable. The chi-square test were used to assess differences in the distribution of categorical variables; t-tests done to compare continuous variables. Multivariate regression analysis were performed in order to identify independent predictors of in-hospital mortality.

\section{Results:}

In the present study mean age of the male patients were lower $(56.10 \pm 11.86$ years) than that of the female patients (57.83 \pm 13.74 years), but the mean defference was not statistically significant ( $p>0.05 \%$ ) (Table-I). There was no significant difference regarding risk factors among the studied patients $(p>0.05)$ and smoking was higher in both groups (Table-II).

Regarding biochemical, hemodynamic and echocardiographic parameter of the study population, it was found that the mean percentage of ejection fraction in hyperglycemic patients of group 1B (Non diabetic with stress hyperglycemia e"11.1) were $40.88+6.86$ and in group 2B (DM with hyperglycemia) were $46.00 \pm 7.89$ (Table -III).The difference between two groups of patients were statistically highly significant $(p<0.001)$.
In this study it was found that LV dysfunction were significantly more common in group $1 \mathrm{~B}$ in terms of mild $(p<0.05)$ and moderate $(p<0.001)$ LV dysfunction than in group 2B.But there was no significant difference in severe LV dysfunction ( $p>0.05)$ among both groups. LV dysfunction were significantly more common in group 1B (Hyperglycemic non diabetic in terms of mild $(p<0.0001)$ and moderate $(p<0.0001)$ LV dysfunction than in group $1 \mathrm{~A}$ (controlled).But there was no significant difference in severe LV dysfunction ( $p>0.05)$ among both groups. LV function were significantly normal $(p<0.05)$ in non-diabetic normal glycemic group $1 \mathrm{~A}$ (Table IV)

In this study also showed that regarding in-hospital adverse outcome, death was significantly higher in hyperglycemic non diabetic group $(p<0.0001)$ than hyperglycemic diabetic group. It was two times (56\%) higher than diabetic hyperglycemic (28\%) group.In addition in this study we also found that cardiogenic shock $(66 \%)$ and $\mathrm{CHF}$ (56\%) were also more common in hyperglycemic non diabetic group than hyperglycemic diabetic group in which cardiogenic shock (44\%) and CHF (34\%) (Table-V, $\mathrm{VI})$. In this study Out of 200 patients, 50 of them were non diabetic with hyperglycemia among them that the highest 28 patients died of AMI with stress hyperglycemia without DM $(p<0.0001)$ than those of patients of AMI with or without

Table-I

Age and sex distribution of the study patients of both groups $(n=200)$

\begin{tabular}{|c|c|c|c|c|c|}
\hline \multirow[t]{3}{*}{ Age in Years } & \multicolumn{4}{|c|}{ Study Subject } & \multirow[t]{3}{*}{$\mathrm{P}$ value } \\
\hline & \multicolumn{2}{|c|}{ Male } & \multicolumn{2}{|c|}{ Female } & \\
\hline & No. & $\%$ & No. & $\%$ & \\
\hline$<45$ & 19 & 11.1 & 04 & 13.8 & 0.752 \\
\hline 45- 54 & 51 & 29.8 & 07 & 24.1 & 0.533 \\
\hline $55-64$ & 61 & 35.7 & 07 & 24.1 & 0.225 \\
\hline$\geq 65$ & 40 & 23.4 & 11 & 37.9 & 0.097 \\
\hline Mean \pm SD & \multicolumn{2}{|c|}{$56.10 \pm 11.86$} & \multicolumn{2}{|c|}{$57.83 \pm 13.74$} & 0.48 \\
\hline
\end{tabular}

Table-II

Risk factor distribution of study subject $(n=200)$

\begin{tabular}{|c|c|c|c|c|c|c|c|c|c|}
\hline \multirow[t]{3}{*}{ Risk factors } & \multicolumn{8}{|c|}{ Study subject $(n=200)$} & \multirow[t]{3}{*}{$P$ value } \\
\hline & \multicolumn{2}{|c|}{ Group1A } & \multicolumn{2}{|c|}{ Group1B } & \multicolumn{2}{|c|}{ Group2A } & \multicolumn{2}{|c|}{ Group2B } & \\
\hline & No. & $\%$ & No & $\%$ & No & $\%$ & No & $\%$ & \\
\hline Smoking & 38 & 26.0 & 40 & 27.4 & 35 & 24.0 & 33 & 22.6 & 0.401 \\
\hline HTN & 07 & 14.9 & 11 & 23.4 & 14 & 29.8 & 15 & 31.9 & 0.230 \\
\hline Dyslipidaemia & 02 & 11.8 & 04 & 23.5 & 05 & 29.4 & 06 & 35.3 & 0.522 \\
\hline Family History & 02 & 14.3 & 04 & 28.6 & 03 & 21.4 & 05 & 35.7 & $0.674^{\mathrm{N}}$ \\
\hline
\end{tabular}

Group 1A: Non-diabetic with RBS<11.1 mmol//, Group 1B: Non-diabetic with RBS >11.1 mmol//

Group 2A: Diabetic with RBS < $11.1 \mathrm{mmol} / \mathrm{l}$, Group 2B: Diabetic with RBS e" $11.1 \mathrm{mmol} /$ 
hyperglycemia with DM. Lowest patients (8\%) died of AMI without DM with random blood glucose $<11.1 \mathrm{mmol} / \mathrm{l}$ (controlled). On the other hand highest improvement was in the controlled group $(p<0.0001)$. ).So that the result was statistically highly significant.

Multivariate analysis identified several variables that were independently associated with in-hospital mortality. Diabetic status with normal blood sugar was a predictor of adverse outcome; but patients with hyperglycemia and no history of diabetes had a worse outcome and were independently associated with significant risk of in-hospital mortality. Group $1 \mathrm{~A}$ (Non-diabetic and RBS $<11.1 \mathrm{mmol} / \mathrm{L}$ ) was considered as reference category for the 'Groups' as variable. Age group (>65 years) and Male sex were also associated with significant in-hospital mortality. In case of age groups '<45 years' was considered as reference category (OR 0.17 ; $95 \% \mathrm{Cl} 0.05-0.59$ in group1B and OR 3.02; 95\% Cl 1.237.41 in group2A) (Table-VII).

Table-III

Biochemical, Hemodynamic, Echocardiography and Other parameters of study subject $(n=200)$

\begin{tabular}{|c|c|c|c|c|c|}
\hline \multirow[t]{3}{*}{ Parameters } & \multicolumn{4}{|c|}{ Study subject $(n=200)$} & \multirow[t]{3}{*}{$P$ value } \\
\hline & Group1A & Group1B & Group2A & Group2B & \\
\hline & Mean \pm SD & Mean \pm SD & Mean \pm SD & Mean \pm SD & \\
\hline S.Creatinine $(\mathrm{mmol} / \mathrm{L})$ & $0.95 \pm 0.23$ & $1.13 \pm 0.17$ & $1.10 \pm 0.19$ & $1.17 \pm 0.53$ & $0.004^{S}$ \\
\hline Diastolic BP (mm Hg) & $68.5 \pm 14.53$ & $58.4 \pm 32.03$ & $61.5 \pm 30.7$ & $67.5 \pm 26.23$ & $0.203^{\mathrm{NS}}$ \\
\hline Systolic BP (mm Hg) & $102.6 \pm 22.86$ & $89.2 \pm 49.89$ & $94.9 \pm 48.1$ & $103.5 \pm 42.55$ & $0.286^{\mathrm{NS}}$ \\
\hline Ejection Fraction (\%) & $48.34 \pm 5.05$ & $40.88 \pm 6.86$ & $46.4 \pm 6.8$ & $46.0 \pm 7.9$ & $0.0001^{\mathrm{S}}$ \\
\hline Weight (kg) & $63.96 \pm 7.88$ & $62.26 \pm 6.57$ & $61.06 \pm 5.68$ & $64.44 \pm 6.65$ & $0.049^{s}$ \\
\hline Hospital Stay (days) & $5.96 \pm 1.89$ & $4.0 \pm 2.1$ & $4.66 \pm 1.63$ & $4.74 \pm 1.91$ & $0.0001^{\mathrm{s}}$ \\
\hline
\end{tabular}

Group 1A: Non-diabetic with RBS<11.1 mmol//, Group 1B: Non-diabetic with RBS $\geq 11.1 \mathrm{mmol} / \mathrm{l}$

Group 2A: Diabetic with RBS < $11.1 \mathrm{mmol} / \mathrm{l}$,Group 2B: Diabetic with RBS $\geq 11.1 \mathrm{mmol} /$

$P$ value reached from one way ANOVA

Table-IV

In-hospital outcome of hyperglycemic patients $(n=100)$

\begin{tabular}{lccccc}
\hline Outcome & \multicolumn{2}{c}{ Study Subject } & \multicolumn{2}{c}{$p$ value } \\
\cline { 2 - 4 } & \multicolumn{2}{c}{ Group 1B $(\mathrm{n}=50)$} & & Group 2B $(\mathrm{n}=50)$ \\
\cline { 2 - 5 } & No. & $\%$ & & No. & \% \\
\hline Improved & 22 & 44.0 & 36 & 72.0 & 0.005 \\
C.Shock & 33 & 66.0 & 22 & 44.0 & 0.027 \\
CHF & 28 & 56.0 & 17 & 34.0 & 0.027 \\
Tachyarrythmia & 03 & 06.0 & 05 & 10.0 & 0.715 \\
Bradyarrythmia & 05 & 10.0 & 05 & 10.0 & 1.000 \\
Thormboembolism & 00 & 00.0 & 01 & 02.0 & 1.000 \\
Death & 28 & 56.0 & 14 & 28.0 & 0.005 \\
\hline
\end{tabular}

Table-V

In-hospital outcome of non diabetic patients $(n=100)$

\begin{tabular}{|c|c|c|c|c|c|}
\hline \multirow[t]{3}{*}{ Outcome } & \multicolumn{4}{|c|}{ Study Subject } & \multirow[t]{3}{*}{$p$ value } \\
\hline & \multicolumn{2}{|c|}{ Group 1A $(n=50)$} & \multicolumn{2}{|c|}{ Group 1B (n=50) } & \\
\hline & No. & $\%$ & No. & $\%$ & \\
\hline Improved & 46 & 92.0 & 22 & 44.0 & 0.0001 \\
\hline C.Shock & 13 & 26.0 & 33 & 66.0 & 0.0001 \\
\hline $\mathrm{CHF}$ & 13 & 26.0 & 28 & 56.0 & 0.002 \\
\hline Tachyarrhythmia & 03 & 06.0 & 03 & 06.0 & 1.000 \\
\hline Bradyarrythmia & 06 & 12.0 & 05 & 10.0 & 0.749 \\
\hline Thormboembolism & 04 & 08.0 & 00 & 00.0 & 0.117 \\
\hline Death & 04 & 08.0 & 28 & 56.0 & 0.0001 \\
\hline
\end{tabular}

Group 1B: Non diabetic with RBS $\geq 11.1 \mathrm{mmol} / \mathrm{l}$, Group $1 \mathrm{~A}$ : Non diabetic with $\mathrm{RBS}<11.1 \mathrm{mmol} / \mathrm{l}$ 
Table-VI

In-hospital outcome of diabetic patients $(n=100)$

\begin{tabular}{|c|c|c|c|c|c|}
\hline \multirow[t]{3}{*}{ Outcome } & \multicolumn{4}{|c|}{ Study Subject } & \multirow[t]{3}{*}{$p$ value } \\
\hline & \multicolumn{2}{|c|}{ Group 2A $(n=50)$} & \multicolumn{2}{|c|}{ Group 2B $(n=50)$} & \\
\hline & No. & $\%$ & No. & $\%$ & \\
\hline Improved & 40 & 80.0 & 36 & 72.0 & 0.349 \\
\hline C.Shock & 15 & 30.0 & 22 & 44.0 & 0.147 \\
\hline $\mathrm{CHF}$ & 11 & 24.0 & 17 & 34.0 & 0.271 \\
\hline Tachyarrhythmi & 01 & 02.0 & 05 & 10.0 & 1.204 \\
\hline Bradyarrythmia & 04 & 08.0 & 05 & 10.0 & 1.000 \\
\hline Thormboembolism & 01 & 02.0 & 01 & 02.0 & 1.000 \\
\hline Death & 10 & 20.0 & 14 & 28.0 & 0.349 \\
\hline
\end{tabular}

Group 2A: Diabetic with RBS < $11.1 \mathrm{mmol} / \mathrm{l}$, Group 2B: Diabetic with RBS $\geq 11.1 \mathrm{mmol} / \mathrm{l}$

Table-VII

Independent Predictors of In-hospital mortality $(N=200)$

\begin{tabular}{lccc}
\hline Variables of interest & \multicolumn{3}{c}{ Multivariate Analysis } \\
\cline { 2 - 4 } & Odds ratio & $95 \%$ Cl for OR & P value \\
\hline Group 1A & 1.00 & $0.14-0.64$ & 0.07 \\
Group 1B & 0.17 & $0.05-0.59$ & 0.005 \\
Group 2A & 3.02 & $1.23-7.41$ & 0.015 \\
Group 2B & 0.48 & $0.18-1.28$ & 0.143 \\
Age group $>50$ yrs) & 4.21 & $1.03-17.11$ & 0.044 \\
Sex (Male) & 0.17 & $0.04-0.67$ & 0.011 \\
Smoking & 3.07 & $0.90-10.49$ & 0.073 \\
HTN & 1.42 & $0.6-3.36$ & 0.425 \\
Dyslipidaemia & 2.76 & $0.66-11.65$ & 0.165 \\
Family history of IHD & 1.96 & $0.47-8.16$ & 0.354 \\
\hline
\end{tabular}

Group 1A: Non-diabetic with RBS<11.1 mmol//, Group 1B: Non-diabetic with RBS >11.1 mmol//

Group 2A: Diabetic with RBS $<11.1 \mathrm{mmol} / \mathrm{l}$, Group 2B: Diabetic with RBS $\geq 11.1 \mathrm{mmol} /$

\section{Discussion}

The present study was a prospective observational study conducted in the National Institute of Cardiovascular Diseases (NICVD), Dhaka. The aim of the study was to assess the prognostic significance of on admission blood glucose level with ST-segment elevation AMI patients with or without history of DM who received thrombolytic.

In the present study mean age of the male patients were lower (56.10 \pm 11.86 years) than that of the female patients (57.83 \pm 13.74 years), but the mean defference was not statistically significant ( $p>0.05 \%)$. In this study out of two hundred patients 171 (85\%) were male and 29(15\%) were female.There was no significant difference regarding risk factors among the studied patients $(p>0.05)$ and smoking was higher in both groups. In this study shows that LV dysfunction were significantly more common in group $1 \mathrm{~B}$ in terms of mild $(p<0.05)$ and moderate $(p<0.001)$ LV dysfunction than in group $2 B$. But there was no significant difference in severe LV dysfunction $(p>0.05)$ among both groups.

Another study showed that high admission blood glucose level $(A B G)$ levels could be a marker of high-risk patients with excess stress response mediated by neurohormonal system activation, particularly cortisol and catecholamine's. ${ }^{12}$ Furthermore, impaired myocardial performance results in the activation of compensatory neurohormonal systems, including activation of the sympathetic nervous system, with the degree of sympathetic activation being proportional to the severity of ventricular dysfunction and degree of HF. ${ }^{13}$ Activation of the sympathetic system not only increases insulin resistance but also 
decreases the release of insulin from the pancreatic beta cells and increases hepatic glucose production by stimulating both gluconeogenesis and glycogenolysis. ${ }^{14,15}$ However, hyperglycemia may contribute to exacerbation of HF by several independent mechanisms.

Multivariate analysis identified several variables that were independently associated with in-hospital mortality. Diabetic status with normal blood sugar was a predictor of adverse outcome; but patients with hyperglycemia and no history of diabetes had a worse outcome and were independently associated with significant risk of inhospital mortality. Group $1 \mathrm{~A}$ (Non-diabetic and RBS $<11.1 \mathrm{mmol} / \mathrm{L}$ ) was considered as reference category for the 'Groups' as variable. Age group (>50 yrs) and Male sex were also associated with significant in-hospital mortality.

\section{Conclusion:}

From this study it may be concluded that, independent of diabetic status, the occurrence of hyperglycemia during AMI is associated with a sub-population of patients at particularly high risk for an adverse clinical outcome. In this study we found that in-hospital death was significantly higher in hyperglycemic non diabetic group $(p<0.0001)$ than hyperglycemic diabetic group. It was two times (56\%) higher than diabetic hyperglycemic (28\%) group.This study may be the base of further clinical controlled studies with larger population to validate our findings.

\section{Limitations of the study}

Although the results of this study support the hypothesis, yet this has got some limitations. The study was a nonrandomized and observation study, Number of study population was limited. We could not determine the true incidence of diabetes mellitus, especially among persons without a prior history of this condition. Finally no attempt was made to analyze sequential glucose levels in the hospital, and thus we have no information on the outcome of patients who may have developed hyperglycemia later in their hospital course.

\section{References:}

1. Hammoud, T, Tanguay, JF\& Bourassa, MG 2000, Management of coronaryartery disease: therapeutic options in patients with diabetes, 'J Am CollCardiol, vol. 36, pp 355-65.

2. Norhammer, AM, Ryden, L\& Malmberg, K 1999, 'Admission plasmaglucose. Independent risk factor for long-term prognosis after myocardial infarction even in nondiabetic patients,' Diabetes Care, vol .22, pp. 1827-31.

3. Capes, SE, Hunt, D, Malmberg, K \& Gerstein, HC 2000, 'Stresshyperglycaemia and increased risk of death after myocardial infarction inpatients with and without diabetes: a systematic overview,' Lancet, vol. 356, pp 773-8.
4. Timmer, JR, van der, Horst IC\&Ottervanger, JP2004, 'Prognostic value of admission glucose in non diabetic patients with myocardial infarction .' $A m$ Heart J, vol.148, pp.399-404.,

5. Ceriello, A 2005, 'acute hyperglycemia: a 'new' risk factor during myocardial infarction.'Eur Heart $J$ ,vol.26.pp.328-31.

6. Smith, J\&Romijn,J 2006, 'Acute insulin resistance in myocardial ischemia: causes and consequences,' Semin Cardiothorac Vasc Anesth, vol.10,pp.215-9.

7. Roglic, G,Unwin,N, Bennet, PH,Tuomilehto,J,Nag,S, Connolly. V \& King, H 2005, 'The Burden of Mortality Attributable to Diabetes Realistic estimates for the year 2000,'Diabetes Care, vol.28,pp.2130-2135.

8. Petursson, P, Herlitz, J, Caidahl, K, Gudbjornsdottir, S, Karlsson, T, Perers, E, Sjoland, H \&Hartford 2007, 'Admission glycemia and outcome after acute coronary syndrome,'Int J cardio, vol.116, pp.315320.

9. Gupta, MS, Yadav, RK \& Singh, H 2008, 'Glucose Tolerance in Non-Diabetic Patients with Acute Myocardial Infarction-A Short Term Follow-up Study,' JIACM, v.9, p.15-9.

10. Mamun, SK 2007, 'Angiographic comparison of coronary artery diseasebetween diabetic men and women,' MD (Cardiology) thesis, NICVD, Dhaka, p.17.

11. Asaduzzaman, K 2008, 'Impaired fasting glucose and cardiogenic shock in patients with acute myocardial infarction,'MD cardiology Thesis, Sir Salimullah Medical College Mitford, Dhaka, Bangladesh, p.79.

12. Oswald, GA, Smith, CCT, Betteridge, DJ \& Yudkin, JS 1986, 'Determinants and importance of stress hyperglycaemia in non-diabeticpatients withmyocardial infarction,' Br J Med, vol. 293, pp .917-22.

13. Benedict, CR,Weiner,DH,\&Johnstone,DE 1993, 'Comparative neurohormonal responses in patients with preserved and impaired left ventricular ejection fraction: results of the Studies of Left Ventricular Dysfunction(SOLVD)Registry,' AM Coll Cardiol,vol.22,pp146A-153A.

14. Rizza ,RA, Cryer, PE, Haymond ,MW\& Gerich, JE 1980, 'Adrenergic mechanisms for the effects of epinephrine on glucose production and clearance in man'. J Clin Invest, vol.65, pp.682-689.

15. Delbert,DC, DeFronzo ,RA 1980, Epinephrineinduced insulin resistance in man'. J Clin Invest, vol.65, pp.717-721. 